Original Article

\title{
NEEDS AND UTILIZATION OF DRUG-INFORMATION RESOURCES OF HEALTHCARE PROVIDERS IN AN ACADEMIC TERTIARY CARE CENTER
}

\author{
YOUSIF S. ALAKEEL ${ }^{1,2,3}$, DIYANA ALMUTAIRI'2, LAILA LAYQAH ${ }^{1,3}$
}

${ }^{1}$ King Saud Bin Abdulaziz University for Health Sciences, College of Pharmacy, Riyadh, Saudi Arabia, ${ }^{2}$ King Abdulaziz Medical City, Pharmaceutical Care Department, Division of Clinical Pharmacy, Riyadh, Saudi Arabia, ${ }^{3}$ King Abdullah International Medical Research Center, Riyadh, Saudi Arabia

Email: alaqeely@ksau-hs.edu.sa

Received: 18 May 2020, Revised and Accepted: 19 Jun 2020

\section{ABSTRACT}

Objective: To investigate the drug-related information needs of healthcare providers (HCPs), their utilization of drug information resources as well as the main factors influencing the selection of resources.

Methods: A total of 393 HCPs were conveniently selected and invited to complete a questionnaire. Stratified sampling was used for the three subpopulations of physicians, pharmacists, and nurses. The questionnaire was coded, validated, and analyzed using the Statistical Package for the Social Sciences (SAS version 9.2).

Results: Of 450 HCPs approached, 393 completed the questionnaire (response rate 87\%). Information related to drug dosage/administration indications, and interactions is the most frequently required, $47 \%, 44 \%$, and $34 \%$, respectively. The majority of the sample perceived the Internet $(69.47 \%)$ and electronic databases (67.43\%) as "very useful." Printed materials (46.56\%) and Personal Digital Assistants (PDAs) (44.78\%) or calling the pharmacy (43.26\%) were also useful resources of information followed by using electronic books and journals (38.42\%) and asking colleagues (32.32\%). The majority (53.18\%) described consulting a clinical pharmacist as "very useful." However, 16\% of the nurse group and 35\% of the physician group were not aware of the existence of the Drug Information Center (DIC) and more than 8\% of the participants consider calling the DIC about drug-related information "not useful".

Conclusion: Digital resources are used by HCPs more frequently than traditional resources, consulting a clinical pharmacist or calling the DIC Providing reliable electronic resources and raising the awareness of HCPs regarding the role of a clinical pharmacist and DIC for patient-specific therapies should be instituted.

Keywords: Drug Information Services, Health Care Providers, Clinical Pharmacist, Electronic Database, Drug Information Center

(c) 2020 The Authors. Published by Innovare Academic Sciences Pvt Ltd. This is an open access article under the CC BY license (http://creativecommons.org/licenses/by/4.0/) DOI: http://dx.doi.org/10.22159/ijpps.2020v12i8.38363. Journal homepage: https://innovareacademics.in/journals/index.php/ijpps.

\section{INTRODUCTION}

Medical knowledge is expanding exponentially, especially in the field of therapeutics [1]. The range of drug-related research and new drug discoveries are generating information overload, difficult for healthcare providers (HCPs) to manage to deliver optimal patient care. They are responsible to keep up-to-date with new information and knowledge, but it has become difficult due to the limitations of human memory [2, 3]. HCPs have to rely on information resources to provide support in delivering healthcare [4].

Literature is available regarding the information needs of HCPs [57]. The majority reported that the most frequent information required by physicians is related to the treatment of diseases [8]. In two highly-cited studies, primary care physicians were interviewed after each patient consultation and asked about the questions raised as a result of the consultation [5, 9]. González et al. found that the most frequent questions were related to diagnosis (53\%), and treatment (26\% [9]. However, Cogdill et al. [5]. Reported that drug therapy-related information was most frequently required (30\%). Nurses also most frequently required drug therapy information [10]. The literature review did not reveal any studies related to the information needs of pharmacists.

With the diversity of available resources, including human (e. g. colleagues, other clinical staff), paper-based references (e. g. journals, textbooks), and electronic sources (digital libraries, electronic devices), HCPs have various options available. From the 1970s, several studies evaluated the use of information resources, which are increasing due to advances in technology [4, 8, 9, 11-15]. Before 2000 HCPs relied mostly on colleagues and textbooks for information despite the introduction of the Internet in the late 1990s [16]. A review article, including studies from 2000 to 2006 showed that the most frequently used information resource was still a textbook $(39 \%)$, followed by humans (25\%), with users' dependence on computers only $13 \%$ [8]. Currently, an increase in the use of computer-based resources has been reported (53\%) compared to other resources [7]. According to a study done in Hong-Kong, of a list of the 10 topics for which information could be required, information related to drug dosage and alternative medicines were the most frequent $(20 \%$ and $13 \%$ respectively). Most of these questions were asked telephonically, but electronic resources were also used frequently.

Only a few studies investigating the type of information resources and drug information required by HCPs have been published in Saudi Arabia. Abou-Auda (2008) surveyed more than 1200 physicians in different healthcare settings and reported that books (79\%) and journals $(60 \%)$ were the most trusted and used resources. Information required was related to complementary/herbal medicines $(50 \%)$ as well as caution, contraindications, and adverse effects (49\%). The majority (70\%) of the sample was aware of the DIC, but not of the type of services provided by the DIC [15]. In contrast, Almazrou et al. (2019) reported that two-thirds of the information required was related to drug dosage and administration, followed by drug-drug interaction $(58.7 \%)$ and adverse events (37\%). The sample mainly used electronic resources, with UpToDate $₫$ the preferred database. In addition, most of the sample (62.9\%) was aware of the DIC. However, of this group, $52 \%$ have never contacted the DIC for drug information since they started their professional practice [17].

Though the practices of physicians related to drug information resources and services have been reported in international literature, there is still a paucity of data investigating HCPs' needs 
and utilization of available drug-information resources after the increase of online and electronic resources. The current study used a validated questionnaire aiming to obtain insight into the drug information needs and use by HCPs in this era of online availability. In addition, the perceptions of HCPs of the DIC and the clinical pharmacist as a source of information, and the factors associated with their choice of resource, were explored.

\section{MATERIALS AND METHODS}

This observational cross-sectional study was conducted at King Abdulaziz Medical City, Riyadh (KAMC-R), from June to September 2018. KAMC is a governmental, teaching tertiary-care hospital providing healthcare services to the Saudi National Guard (NG) members, as well as non-NG patients referred to the hospital for healthcare.

\section{Sample size}

The sample was calculated as follows: assuming a two-sided test, $95 \%$ confidence interval, and $80 \%$ power, for a single proportion, the number of participants needed was 393. Based on the total number of employees at KAMC-R, the sample size was stratified as 254 nurses, 119 physicians, and 20 pharmacists.

\section{Data collection}

Data were collected with a self-administered questionnaire constructed by the study team, which was conveniently distributed to the chosen HCPs (physicians, nurses, and pharmacists). Medical and pharmacy interns, students, and part-time employees were excluded. Participants were assured of anonymity and confidentiality. The data were collected $5 \mathrm{~d}$ per week, for four months. The participants gave informed consent before completing the questionnaire. The process lasted less than $30 \mathrm{~min}$.

\section{The questionnaire}

The questionnaire consisted of 12 questions, categorized in three sections. The first section focused on the demographic background gender, age, professional specialty, the country of the last qualification, degree obtained, and years of experience (table 1). The second section focused on the need of the HCPs for drug-related information and the type of information required in their practice. The third section explored the drug information resources according to the type of information, as well as the frequency of using specific resources of drug information and their usefulness. The questionnaire was validated in a pilot study with HCPs working at KAMC-R.

\section{Data analysis}

The data were analyzed with SAS version 9.2 (SAS Institute Inc., Cary, NC). All variables were summarized and reported with descriptive statistics. Interval variables such as age and time are reported as frequency and percentage. Categorical variables such as gender, specialty, job title, place of the last qualification, and years of experience are reported as a proportion of the total ( $\mathrm{n} \%$ ). The relationship between variables was analyzed using a chi-square test. The results are reported in terms of frequency, percentage, and pvalue. All statistical tests were considered significant at an $\alpha$ level of 0.05 or less.

\section{Ethics approval}

Ethical approval for the study was obtained from the Institutional Review Board of King Abdullah International Medical Research Center, Riyadh, Saudi Arabia (IRB approval No. RC13/181).

\section{RESULTS}

Of 450 HCPs approached, 393 completed the questionnaire. The overall response rate was $87 \%$.

Table 1 displays the demographic and educational characteristics of the sample. The majority were nurses $(65 \%)$, female $(67.7 \%)$, and younger than $40 \mathrm{y}(66 \%)$. Asia is the most frequent country where the last qualification was obtained $(38.68 \%)$, followed by Saudi Arabia (37.15\%). A third of the sample (30\%) had 6-10 $\mathrm{y}^{\prime}$ experience, with a small proportion $(6.87 \%)$ more than $20 \mathrm{y}$, and $15.27 \%$ had less than $2 \mathrm{y}$ of experience.

Table 2 represents the types and frequency of drug information queries. More than one-third $(34.35 \%)$ of the sample required drug-related information 3 to 5 times weekly. Information related to drug dosage/administration, indications, and interactions were the most frequently required by the HCPs, $47 \%, 44 \%$, and $34 \%$ respectively.

Regarding the usefulness of the available drug information resources, the majority of the sample considered the Internet $(69.47 \%)$ and electronic databases $(67.43 \%)$ as "very useful" and were most likely to use them on a daily or weekly basis (table 3 and 4). Using printed materials (46.56\%), Personal Digital Assistants (PDAs) $(44.78 \%)$, or calling the pharmacy $(43.26 \%)$ were the second most useful resources followed by electronic books and journals (38.42\%) and asking colleagues (32.32\%) (table 4).

Table 1: Demographic characteristics of the study cohort

\begin{tabular}{|c|c|c|c|c|}
\hline & Total $(n=393)$ n (\%) & Nurses (n=254) n (\%) & Physicians (n=119) n (\%) & Pharmacists $(n=20) n(\%)$ \\
\hline \multicolumn{5}{|r|}{$x_{2} x_{2}$} \\
\hline$\leq 30$ & $132(33.59)$ & $77(30.31)$ & $42(35.29)$ & $13(65.0)$ \\
\hline $31-39$ & $129(32.82)$ & $85(33.46)$ & 37 (31.09) & $7(35.0)$ \\
\hline $40-49$ & $107(27.23)$ & $75(29.53)$ & $32(26.89)$ & $0(0.00)$ \\
\hline$\geq 50$ & $25(6.36)$ & $17(6.69)$ & $8(6.72)$ & $0(0.00)$ \\
\hline \multicolumn{5}{|l|}{ Gender } \\
\hline Female & $266(67.68)$ & $231(90.94)$ & $23(19.33)$ & $12(60.0)$ \\
\hline Male & $127(32.32)$ & $23(19.33)$ & $96(80.67)$ & $8(40.0)$ \\
\hline \multicolumn{5}{|c|}{ Place of the last qualification } \\
\hline Asia & $152(38.68)$ & $144(56.69)$ & $8(6.72)$ & $0(0.00)$ \\
\hline Saudi Arabia & $146(37.15)$ & $70(47.95)$ & $56(38.36)$ & $20(13.69)$ \\
\hline Middle East & $31(7.89)$ & $14(5.51)$ & 17 (14.29) & $0(0.00)$ \\
\hline Europe & $24(6.11)$ & $12(4.72)$ & $12(10.08)$ & $0(0.00)$ \\
\hline Africa & $22(5.60)$ & $10(3.94)$ & $12(10.08)$ & $0(0.00)$ \\
\hline Canada & $13(3.31)$ & $3(1.18)$ & $10(8.40)$ & $0(0.00)$ \\
\hline USA & $5(1.27)$ & $1(0.39)$ & $4(3.36)$ & $0(0.00)$ \\
\hline \multicolumn{5}{|c|}{ Total years of experience } \\
\hline $1-2$ & $60(15.27)$ & $21(8.27)$ & $30(25.21)$ & $9(45.0)$ \\
\hline $3-5$ & $94(23.92)$ & $66(25.98)$ & $21(17.65)$ & $7(35.0)$ \\
\hline $6-10$ & $116(29.52)$ & $80(31.50)$ & $33(27.73)$ & $3(15.0)$ \\
\hline $11-20$ & $96(24.43)$ & $68(26.77)$ & 27 (22.69) & $1(5.0)$ \\
\hline$>20$ & $27(6.87)$ & $19(7.48)$ & $8(6.72)$ & $0(0.00)$ \\
\hline \multicolumn{5}{|c|}{ Are you aware of the existence of the Drug Information Center at KAMC? } \\
\hline Yes & $309(78.63)$ & $213(83.86)$ & $77(64.71)$ & $19(95.0)$ \\
\hline No & $84(21.37)$ & $41(16.14)$ & $42(35.29)$ & $1(5.0)$ \\
\hline
\end{tabular}


Table 2: Types of drug information required

\begin{tabular}{|c|c|c|c|c|c|}
\hline & Once/week n (\%) & Twice/week n (\%) & $\begin{array}{l}\text { 3-5 times/week n } \\
(\%)\end{array}$ & $\begin{array}{l}\geq 6 \text { times/week n } \\
(\%)\end{array}$ & \\
\hline $\begin{array}{l}\text { Frequency of information } \\
\text { seeking/week }\end{array}$ & 110 (27.99) & $67(17.05)$ & $135(34.35)$ & $81(20.61)$ & NA \\
\hline Type of drug information & Always n (\%) & Frequently n (\%) & Sometimes n (\%) & Rarely n (\%) & Never n (\%) \\
\hline Dosage/administration & $183(46.56)$ & $91(23.16)$ & $98(24.94)$ & $20(5.09)$ & $1(0.25)$ \\
\hline Drug interactions & $135(34.35)$ & $99(25.19)$ & 117 (29.77) & $41(10.43)$ & $1(0.25)$ \\
\hline Pharmacology/toxicology & $103(26.21)$ & $81(20.61)$ & $141(35.87)$ & $65(16.54)$ & $3(0.76)$ \\
\hline Drug indication & $172(43.77)$ & $89(22.65)$ & $76(19.34)$ & $49(12.47)$ & $7(1.78)$ \\
\hline Pregnancy/lactation & $75(19.08)$ & $61(15.52)$ & $128(32.57)$ & $93(23.66)$ & $36(9.16)$ \\
\hline $\begin{array}{l}\text { Pharmacokinetics/toxic } \\
\text { kinetics }\end{array}$ & $85(21.63)$ & $59(15.01)$ & $138(35.11)$ & $85(21.63)$ & $26(6.62)$ \\
\hline Laboratory test interference & $63(16.03)$ & 55 (13.99) & $141(35.88)$ & $97(24.68)$ & $37(9.41)$ \\
\hline Complementary therapies & $60(15.27)$ & $64(16.28)$ & $128(32.57)$ & $92(23.41)$ & $49(12.47)$ \\
\hline
\end{tabular}

Table 3: Frequency of drug information resources used

\begin{tabular}{|c|c|c|c|c|}
\hline Frequently uses of resources & Daily n (\%) & Weekly n (\%) & Monthly n (\%) & Never n (\%) \\
\hline Humans/colleagues & $97(24.68)$ & $94(23.92)$ & $46(11.70)$ & $156(39.69)$ \\
\hline Printed resources/books & $156(39.69)$ & $102(25.95)$ & $100(25.45)$ & $35(8.91)$ \\
\hline Internet (Google, Bing,.) & $198(50.38)$ & $128(32.57)$ & $56(14.25)$ & $11(2.79)$ \\
\hline $\begin{array}{l}\text { Electronic databases (Uptodate, Medline, } \\
\text { Cochrane,) }\end{array}$ & $215(54.71)$ & $120(30.53)$ & $36(09.16)$ & $22(5.59)$ \\
\hline $\begin{array}{l}\text { Electronic devices (medical applications: e- } \\
\text { Medicine, Medscape.) }\end{array}$ & $148(37.66)$ & $146(37.15)$ & $65(16.54)$ & $34(8.65)$ \\
\hline Calling Drug Information Center (DIC) & $36(9.16)$ & $60(15.27)$ & $64(16.28)$ & $233(59.29)$ \\
\hline Consulting a clinical pharmacist & $98(24.94)$ & $124(31.55)$ & $108(27.48)$ & $63(16.03)$ \\
\hline
\end{tabular}

Table 4: Usefulness of drug information resources

\begin{tabular}{lcccc}
\hline & \multicolumn{1}{c}{ Very useful n (\%) } & Useful n (\%) & Somewhat useful n (\%) & Not useful n (\%) \\
\hline How do you rate the usefulness of the following drug information sources? & & \\
Humans/colleagues & $127(32.32)$ & $163(41.48)$ & $87(22.14)$ & $16(4.07)$ \\
Printed resources/books & $183(46.56)$ & $150(38.17)$ & $48(12.21)$ & $12(3.05)$ \\
Internet & $273(69.47)$ & $95(24.17)$ & $21(5.34)$ & $4(1.02)$ \\
Electronic databases & $265(67.43)$ & $100(25.45)$ & $26(6.62)$ & $2(0.51)$ \\
Personal digital assistants (PDAs) & $176(44.78)$ & $139(35.36)$ & $63(16.03)$ & $15(3.82)$ \\
Electronic books/journals & $151(38.42)$ & $164(41.73)$ & $66(16.79)$ & $12(3.05)$ \\
Calling Drug Information Center (DIC) & $135(34.35)$ & $125(31.81)$ & $101(25.70)$ & $72(8.14)$ \\
Consulting a clinical pharmacist & $209(53.18)$ & $130(33.08)$ & $47(11.96)$ & $7(1.78)$ \\
Calling the pharmacy & $170(43.26)$ & $167(42.49)$ & $49(12.47)$ & $7(1.78)$ \\
\hline
\end{tabular}

Table 5: Factors associated with the use of electronic vs. printed resource of information

\begin{tabular}{llll}
\hline & OR & 95\% CI (lower limit-upper limit) & p-value \\
\hline Years of experience & 0.776 & $0.494-1.219$ & 0.271 \\
Profession (nurses vs physicians) & 1.144 & $0.380-3.445$ & 0.811 \\
Profession (pharmacists vs physicians) & 0.651 & $0.068-6.216$ & 0.709 \\
\hline
\end{tabular}

$\mathrm{CI}=$ Confidence interval $\mathrm{OR}=$ Odds Ratio

Just more than half of the sample $(53.18 \%)$ described consulting a clinical pharmacist as "very useful" (table 4), with $24.94 \%$ and $31.55 \%$ calling the clinical pharmacist daily or weekly, respectively. A small proportion (16.03\%) have never consulted a clinical pharmacist (table 3).

In terms of the DIC, $8 \%$ of the sample considered calling the DIC "not useful" (table 4). It should be noted that more than $21 \%$ of the sample $(16 \%$ of the nurses and $35 \%$ of the physicians) were not aware of the existence of the DIC at KAMC-R, (table 1) and almost $60 \%$ have never called the DIC (table 3 ).

Regarding the factors associated with the selection of specific drug information resources, years of experience (OR $=0.776,95 \% \mathrm{CI}$ $0.494-1.219$ ), profession (OR $=1.144,95 \%$ CI $0.38-3.445$ ) nurses vs. physicians, and (OR $=0.651,95 \%$ CI $0.068-6.216$ ) for pharmacists vs. physicians did not have a significant effect on the type (electronic vs. printed) of resources used ( $p>0.05$ ) (table 5).

\section{DISCUSSION}

Providing reliable drug information resources is essential to ensure safety and efficacy in the management and treatment of diseases. A DIC plays a major role in providing accurate clinical information to HCPs. However, free online electronic resources have become more attractive than traditional resources. We conducted this study to determine the drug-related information needs of HCPs and to evaluate their use of drug information resources, including the hospital's DIC.

The study had an excellent response rate $(87 \%)$ if compared with Abou-Auda [15] (65.6\%) or Almazrou [17] (50.8\%) but less than Andualem et al. [18] with $96 \%$. Factors contributing to this high response rate can be attributed to easy access to participants with a short questionnaire that was easy to complete.

In the current study, information related to drug dosage, drug administration, indications, and interactions were most frequently 
required by HCPs. Our findings support the study of Almazrou et al. [17] reporting that two-thirds of physician queries were related to drug dosage/administration, drug interaction (58\%), and adverse drug reactions (37\%). In contrast, Abou-Auda [15] found that the information most frequently required was related to complementary/herbal medicine $(50.5 \%)$. The discrepancy between the two studies could be due to the sample used. Almost $30 \%$ of the physicians in the Abou-Auda [15] study were practicing in a rural area of Saudi Arabia, and it is feasible that most queries could be related to complementary medicine.

Comparing our results with international data, Peter et al. reported that the most frequent questions received by the DIC in a tertiary academic hospital were about drug indications, adverse drug reactions, and dosage/administration. This report is consistent with our findings, which may reflect the same setting and level of care of both centers [18]. Another study found that the most frequent need in terms of drug information from HCPs in Hong Kong was related to drug doses and alternative medicine [19]. Alternative medicine is commonly used in Asian countries, reflecting the prevalent use of these remedies in Asian people. Clarks et al. [7], in their literature review of 46 articles, found that the information required most frequently by physicians and nurses was diagnoses (17 articles) medications (15 articles), and treatment/therapy (14 articles). The sample consisted of primary care physicians and nurses, which may explain the differences in the findings of this review and our study, which was conducted in a tertiary healthcare center.

Using online resources to obtain drug-related information was frequent in the current study. Searching the Internet and using various electronic databases were used on a daily or weekly basis. Traditional resources such as printed materials, PDAs, or calling the pharmacy were used less frequently and only a third would consult a colleague. In contrast, Koller et al. [20] reported that primary care physicians still preferred textbooks or asking a colleague as sources of drug-related information rather than the Internet. The most frequently used resources were MEDLINE (40\%), online journals (21\%), and the Cochrane Library (14\%). The finding of this study could be attributed to the higher mean age of the sample of $49 \pm 5 \mathrm{y}$.

Almazrou et al. [17] reported similar findings to the current study, electronic resources such as UpToDate ${ }^{\circledR}$ was the preferred database followed by Lexicomp® and Micromedex®. Although a phone call was the most used method reported by Chi-Lien Hou et al. [19] to acquire drug information, electronic resources such as UpToDate $\mathbb{R}$ and Micromedex $\AA$ were also used. Recently, various digital resources and electronic databases became the main source of drug information for different HCPs. Younger practitioners prefer the Internet and advances in technology rather than journals and textbooks. Easy, quick, and inexpensive access, in addition to updated contents, irrespective of accuracy, make the Internet the most popular drug information resource. This statement is supported in the literature. Bennett et al. [20] reported that the majority of physicians use the Internet for updated information regarding patient care. Family practitioners in New Zealand, according to Cullen et al. [21] mainly access the Internet for clinical information related to their patients. Another study conducted by Hailemeskel [19] reported that Google ${ }^{\circledR}$ was a widely accepted resource for drug information for pharmacists. The use of the Internet by clinicians has increased from 20\% (1997) to over $78 \%$ (2002) [22]. The Internet has the potential to become more significant in clinical practice as well as other aspects of healthcare.

The majority of our sample acknowledged the DIC as a source of information. However, $21 \%$ of the sample were not aware of the DIC at KAMC-R despite its active role in managing the hospital drug formulary. Almost 60\% have never called DIC. Abou-Auda [15] also reported a proportion (30\%) not aware of the DIC and $52 \%$ of the HCPs in Almazrou et al. [23] have never contacted DIC. The high prevalence of a lack of awareness and utilization of DIC may be attributed to a lack of orientation to the services provided by the pharmacy. This explanation is supported in the literature reporting that the majority of DIC users were the pharmacist (68\%), followed by the physicians (25\%) [24].

In the current study, years of experience and profession (nurses vs. physicians vs. pharmacists) had no significant effect on the type (electronic vs. printed) of resources used. In contrast, Abou-Auda [25] reported a significant association between years of experience and the physicians' selection of certain resources. Practitioners with longer experience tended to use medical journals or symposia textbooks. Factors affecting the choice of electronic vs. printed resources were not fully investigated in the study because the Internet and electronic resources were not yet popular at the time the study was conducted. In a study with different HCPs from different specialties, drug information needs and searching behavior were significantly affected by work experience and working site. Respondents younger than $30 \mathrm{y}$ were more likely to use the Internet for drug information than the group older than $30 \mathrm{y}$ [26].

The research behavior of young practitioners of new digital resources should be the focus of future research. In addition, more studies are required to investigate the significance of the DIC and clinical pharmacists as drug information resources for HCPs.

\section{LIMITATION}

This survey provides a unique snapshot of the drug information needs and utilization of three major health care professionals; physicians, nurses, and pharmacists. However, the major limitation of our study is the small number of included pharmacists compared to other specialties. This was because we stratified the sample size based on the hospital census of each specialty, and the fact that the pharmacist number at the hospital is much less than the number of either physicians or nurses. Therefore, our findings may not well reflect the pharmacists' needs and perceptions of drug information resources.

\section{CONCLUSION}

Several resources are available to HCPs to provide drug-related information. Drug dosage, methods of administration, indications, and drug-drug interactions are the most frequently required drugrelated information. HCPs, in their daily practice, perceive digital resources as very useful. The Internet and other digital resources are used to obtain drug-related information more often compared to traditional resources such as printed material, consulting a clinical pharmacist, or consulting the DIC. However, it should be noted that the Internet and other electronic open-access resources are not always trustworthy and reliable, and they may provide non-specific patient information. Traditional resources are more trustworthy and usually provide patient-specific information based on the information provided by the HCP. Providing reliable electronic resources and raising the awareness of HCPs of the role of the clinical pharmacist and DIC for patient-specific therapies should be a strategic goal of any institution to enhance safe and effective medication use.

\section{ACKNOWLEDGMENT}

We thank King Abdullah International Medical Research Center (KAIMRC) for funding the project and the healthcare providers who participated in the study. We also appreciate the administration team of the Pharmaceutical Care Department, nurses, and physicians for facilitating communication with the participants.

\section{FUNDING}

This study received support from King Abdullah International Medical Research Center (Grant Budget Approval No. RC13/181/R).

\section{AUTHORS CONTRIBUTIONS}

Dr. Yousif Alakeel contributed to the conception and the study design, supervised the data collection and analysis, and critically revised and drafted the final manuscript and approved it for submission. Dr. Diyana Almutairi contributed to writing the proposal, designed the questionnaires, collected the data, and wrote the first draft of the manuscript. Ms. Laila Layqah participated in data analysis and revised the manuscript.

\section{CONFLICTS OF INTERESTS}

The authors have no conflicts of interest to declare.

\section{REFERENCES}

1. Wyatt J. Information for clinicians. Lancet 1991;338:1368-73. 
2. Mcdonald CJ. Protocol based computer reminders, the quality of care and the non-perfectibility of man. $\mathrm{N}$ Engl J Med 1976;295:1351-5.

3. Weed LL. New connections between medical knowledge and patient care. Br Med J 1997;315:231-5.

4. Rothschild JM. Clinician use of a palmtop drug reference guide. J Am Med Inform Assoc 2002;9:223-9.

5. Cogdill KW, Friedman CP, Jenkins CG, Mays BE, Sharp MC Information needs and information seeking in community medical education. Acad Med 2000;75:484-6.

6. Jerome RN, Giuse NB, Gish KW, Sathe NA, Dietrich MS Information needs of clinical teams: analysis of questions received by the clinical informatics consult service. Bull Med Libr Assoc 2001;89:177-84.

7. Clarke MA, Belden JL, Koopman RJ, Steege LM, Moore JL, Canfield SM, et al. Information needs and information-seeking behaviour analysis of primary care physicians and nurses: literature review. Health Info Libr J 2013;30:178-90.

8. Davies K. The Information-seeking behaviour of doctors: a review of the evidence. Health Info Libr J 2007;24:78-94.

9. Gonzalez Gonzalez Dawes M, Sanchez Mateos M, Riesgo Fuertes R, Escortell Mayor E, Sanz Cuesta T, Hernandez Fernandez T. Information needs and information-seeking behavior of primary care physicians. Ann Fam Med 2007;5:345-52.

10. Cogdill KW. Information needs and Information seeking in primary care: a study of nurse practitioners. J Med Libr Assoc 2003;91:203-15

11. Prendiville TW, Saunders J, Fitzsimons J. The informationseeking behaviour of pediatricians accessing web-based resources. Arch Dis Child 2009;94:633-5.

12. Davies KS. Physicians and their use of information: a survey comparison between the United States, Canada, and the United Kingdom. J Med Libr Assoc 2011;99:88-91.

13. McCord G, Smucker WD, Selius BA, Hannan S, Davidson E Schrop SL, et al. Answering questions at the point of care: do residents practice ebm or manage information sources? Acad Med 2007;82:298-303

14. Andrews JE, Pearce KA, Ireson C, Love MM. Information-seeking behaviors of practitioners in a primary care practice-based research network (PBRN). J Med Libr Assoc 2005;93:206-12.
15. Abou Auda HS. Information-seeking behaviors and attitudes of physicians toward drug information centers in Saudi Arabia. Saudi Med J 2008;29:107-15.

16. Mcknight $M$, Peet $M$. Health care providers information seeking. Med Ref Serv Q 2000;19:27-50.

17. Almazrou DA, Ali S, Al-Abdulkarim D, Albalawi AF, Alzhrani JA Information seeking behavior and awareness among physicians regarding drug information centers in Saudi Arabia. Pharm Pract 2019;17:1498.

18. Peter AV, Murali A, Tomy T, Londhe SP. Assessment and utilization of drug information services and creating awareness for enhanced utilization of drug information centre in a tertiary care teaching hospital. Asian J Pharm Clin Res 2017;10:270-4.

19. Hou CL, LU YH, Chien SC, Chen HH, Chen C. Questions frequently asked of healthcare professionals: a 2 y data survey conducted at a medical center. Biomed Res Int 2018:1-7. https://doi.org/10.1155/2018/4895850.

20. Bennett NL, Casebeer LL, Kristofco RE, Strasser SM. Physicians' internet information-seeking behaviors. J Contin Educ Health Prof 2004;24:31-8.

21. Ali A, Yusoff SM, Joffry SM, Abd Waha SM. Drug Information service awareness program and its impact on characteristics of inquiries at dis unit in Malaysian Public Hospital. Arch Pharm Pract 2013;4:9-14.

22. Cullen RJ. In search of evidence: family practitioners' use of the internet for clinical information. J Med Libr Assoc 2002;90:370-9.

23. Hailemeske B, Drame I, Choi M, Pansiri P. Preferences and utilization of drug information resources by practicing pharmacists. J Nurs Care 2016;2:1-5.

24. Koller M, Grütter R, Peltenburg M, Fischer JE, Steurer J. Use of the internet by medical doctors in switzerland. Swiss Med Wkly 2001;131:251-4.

25. Kwon IWG, Xie HY. Internet use by physicians and its impact on the medical practice-an exploratory study. Health Mark Q 2003;21:5-27.

26. Andualem M, Kebede G, Kumie A. Information needs and seeking behaviour among health professionals working at public hospital and health centers in bahir dar, ethiopia. BMC Health Serv Res 2013:13:534. 